\title{
SUSTENTABILIDADE E TECNOLOGIA NAS OBRAS DE RENZO PIANO
}

\author{
Marco Aurélio Gimenes de Oliveira, Thaís Pichioni Pellozo, Korina Aparecida Teixeira Ferreira da Costa \\ Universidade do Oeste Paulista - UNOESTE, Presidente Prudente, SP. E-mail: thais.pichioni@hotmail.com
}

\begin{abstract}
RESUMO
Neste artigo é proposta a análise e comparação de duas obras expressivas do arquiteto italiano Renzo Piano, seguindo uma linha lógica da corrente High Tech para a Eco Tech. Tal objetivo se obtém através de estudos bibliográficos que fornecem o aporte teórico necessário, além da análise dos projetos em foco: o Centro Nacional de Ciência e Tecnologia (NEMO), em Amsterdã, e a Academia de Ciências Naturais da Califórnia, nos Estados Unidos, de um ponto de vista arquitetônico. Pode-se constatar semelhanças entre os projetos, sobretudo evoluções cronologicamente pontuadas desde o mais antigo ao mais recente. 0 estudo mostra, dessa forma, que é possível compreender um aperfeiçoamento do arquiteto frente às correntes arquitetônicas referidas, tornando mais claras suas intenções e cuidados projetuais mais bem desenvolvidos ao longo do tempo. A teoria de estudo arquitetônico é a Tectônica em consonância com a busca pela diminuição nos impactos ao meio ambiente.
\end{abstract}

Palavras-chave: Sustentabilidade. Estrutura. Tecnologia. Renzo Piano. Tectônica.

\section{SUSTENTABILITY AND TECHNOLOGY IN RENZO PIANO'S WORKS}

\begin{abstract}
In this article, an analysis and comparison of two expressive works by the Italian architect Renzo Piano is proposed, following a logical line of the current High Technology for an Eco Technology. This objective is achieved through bibliographic studies that allow the necessary theoretical detailing, in addition to the analysis of projects in focus: The National Center for Science and Technology (NEMO), in Amsterdam, and the California Academy of Natural Sciences, in the United States, from an architectural point of view. Similarities can be seen between the projects, mainly chronologically punctuated developments from the oldest to the most recent. The study shows, in this way, that it is possible to understand an improvement of the architect in view of the architectural currents, making his intentions and cares more clearly projected over time clearer. The theory of architectural study is Tectonics in line with the search for reduced impacts on the environment.
\end{abstract}

Keywords: Sustainability. Structure. Technology. Renzo Piano. Tectonics.

\section{INTRODUÇÃO}

A necessidade por edificações mais sustentáveis nos últimos anos tem movido pesquisadores e cientistas a desenvolverem materiais que diminuam o impacto ambiental, com menos resíduos e poluentes e que não gerem tantos esforços energéticos, tornando-se mais facilmente degradáveis, nesta linha de pensamento após a arquitetura modernista, novos conceitos de sustentabilidade na construção civil começam a surgir, entre elas o High Tech e sua evolução, o Eco Tech. O High Tech consiste no pensamento de que "A arquitetura deve necessariamente expressar-se na forma estrutural e construtiva." (FRAMPTON, 1997, p. 558).

Segundo Benévolo (2007), a arquitetura ultra tecnicista ou tardo modernista é considerada uma extensão do pensamento moderno, a partir dos anos 1960 e 1970. Essa 
nova arquitetura retoma teorias como a "Estética da Máquina", baseada na tecnologia e no universalismo, racionalidade e funcionalidade, planta livre, separação de estrutura e fechamento, e fachada livre. Além da retomada modernista, novas ideias e conceitos foram buscados pelos ultras tecnicistas, o pensamento utópico junto a tecnologia revoluciona a maneira de projetar desses novos arquitetos.

A arquitetura High Tech caracteriza-se como Perfeccionismo, uso amaneirado e decorativo da tecnologia, com ênfase a proteção física, condicionamento térmico, isolamento acústico, iluminação natural e artificial; Universalismo, despreza a memória histórica contemporânea e de sistemas inteligentes; Experimentalismo, através de atitudes programáticas e tecnocráticas, utiliza suas obras para experimentos; e Abstracionismo, o abandono do inconsciente exposto, para o uso de formas e funções racionais. (BENÉVOLO, 2007).

Dentre os representantes destes pensamentos, estão arquitetos como Richard Rogers, que se dedicou desde o início a alta tecnologia, se destacando pela exposição estrutural e mecânica de seus projetos. "Suas obras são totalmente desprovidas de elementos habituais, como portas e janelas, sendo verdadeiras 'caixas-mágicas', tecnicamente corretas." (FRAMPTON, 1997, p. 560).

Este novo conceito representa um olhar mais crítico sobre questões sociais intrínsecas na arquitetura, a preocupação com ambientes mais sustentáveis é incorporada no ato projetual como uma atitude do projeto. Desta forma os arquitetos High Tech desenvolveram construções inteligentes, que buscam soluções para o desperdício energético, contendo sistemas de termoacumulação e controle de brises, sistema paisagístico interno e externo, e sistema de gerenciamento de infraestrutura. (FRAMPTON, 1997).

Frampton (1997) diz que outro fator social que passou a ser percebido e utilizado como atitude de projeto, foi a preocupação com a análise do lugar e do entorno, portanto o lugar juntamente com o seu entorno, onde o ambiente geográfico não é apenas o local em que a obra será inserida e sim o fator mais relevante para o início do projeto. Com o tempo, no entanto, os princípios da arquitetura High Tech vão se intensificando, a preocupação com a sustentabilidade, com o entorno e com a cultura e memória local torna-se cada vez mais influente no ato projetual, assim a arquitetura passa por um processo evolutivo de sustentabilidade, chegando aos inícios do século XIX com a denominação de arquitetura Eco Tech.

\section{MÉTODOS}

A metodologia desse estudo baseia-se numa investigação bibliográfica, e se fundamenta numa abordagem qualitativa de pesquisas, utilizando-se como instrumentos para levantamento livros, sites, artigos e periódicos a partir da compreensão dos fenômenos, por meio de sua descrição e interpretação. A teoria de estudo arquitetônico é a Tectônica em consonância com a busca pela diminuição nos impactos ao meio ambiente. Para o presente artigo, como estudo do tipo levantamento bibliográfico, tem-se incialmente um levantamento das principais produções no contexto, considerando a peculiaridade do objeto de estudo.

\section{RESULTADOS}

Em termos gerais, a intenção da tectônica é relacionar a arquitetura com o saber-fazer e com as técnicas construtivas, que são normalmente passadas de geração para geração pelos mestres de obras, empreiteiros e técnicos da construção. A tectônica pressupõe que essa posição voltada majoritariamente para a construção seja essencial para a cultura e para a identidade de construção de um povo e deva ser levada em conta pelos arquitetos. "A tectônica considera a mão de obra como um meio de resgate à técnica, ao artesanal e ao tátil por meio do qual a história construtiva de uma determinada cultura manifesta sua identidade". (FRAMPTON, 1997, p. 560).

Segundo Frampton (1997), a composição de materiais e suas aplicações, constitui a base da construção tectônica. A construção compõe a identidade do local, não só pela percepção, mas também pela estrutura física que atende e define o espaço através de elementos técnicos e o caráter representativo estabelecendo a relação com os materiais e os meios construtivos.

O High Tech, abreviatura de High Technology, ocorreu, como tendência arquitetônica, a partir dos anos 70 e se constituiu em uma utilização de métodos, figuras, tecnologia e materiais da arquitetura e engenharia 
industriais em programas comerciais e residenciais urbanos. Caracteriza-se pela exposição dos sistemas técnicos (elétricos, hidráulicos, climatização, circulação), uso intenso de cores vivas e acabamentos metálicos, vedações com painéis industrializados e vidro, nunca com processos tradicionais de alvenaria, por exemplo, grandes vãos e estruturas tensionadas. Esta exposição dos sistemas 2 técnicos foi chamada, jocosamente, de poética do intestinismo. (COLIN, 2000, s/p.)

Para Colin (2000), o High Tech baseia-se em inovações e expressões tecnológicas, semelhante às presentes na indústria, com construções complexas e robustas, porém, com métodos sustentáveis que respeitam o meio ambiente e a preservação de recursos não renováveis, com o aproveitamento da luz natural e ventilação, privilegiando a conexão entre máquinas e pessoas, tendo como principais recursos a utilização do aço e vidro.

Norman Foster é conhecido por projetos tecnológicos e de alta complexidade, o arquiteto inglês é autor de obras mundialmente famosas como a restauração do Reichstag, em Berlim, e o aeroporto de Pequim, na China. Foster foi ganhador do Prêmio Pritzker no ano de 1999. (BENÉVOLO, 2007).

Richard Rogers é um dos arquitetos mais humanistas e sustentáveis do mundo, possui um olhar urbano e expansivo. Nascido em Florenza, na Itália em 1933, cursou arquitetura em Londres, iniciou sua profissão projetando uma residência para a família, que foi destaque pela inovação e tecnologia. Um arquiteto que se destaca pelo uso de diferentes materiais e o uso da mais alta tecnologia, voltada para a sustentabilidade do planeta, produzindo uma arquitetura inovadora e ecologicamente correta, seguindo princípios de eficiência energética através de construções que se utilizam de fontes renováveis de energia - vento, sol e água. Seu ponto de vista do desenvolvimento sustentável depende da: qualidade da arquitetura, bem estar social e responsabilidade ambiental. (BENÉVOLO, 2007).

Premiado arquiteto francês (ganhador do Pritzker em 2008), Jean Nouvel é autor de projetos de formas e texturas não convencionais. Entre eles, a imponente torre Agbar, em Barcelona, o teatro Guthrie, em Minneapolis, e o célebre Instituto do Mundo Árabe, em Paris, que o consagrou em 1987. (BENÉVOLO, 2007).

Nascido em Gênova, na Itália, Renzo Piano cresceu no seio de uma família de construtores. Seu pai e seu avô foram empreiteiros, mas Renzo escolheu quebrar a tradição ao cursar na Escola de Arquitetura do Instituto Politécnico de Milão. Formou-se em 1964, e já na época passou a trabalhar em um projeto de Franco Albini, enquanto também adquiria experiência visitando os edifícios construídos por seu pai. Após esse curto período de estágio, Renzo partiu em viagens de estudos para a Inglaterra e os Estados Unidos e teve a chance de trabalhar com outros arquitetos de renome, como o americano Louis Kahn. (ANACONI, 2018).

Figura 1. Renzo Piano.

Fonte: ANACONI, 2018.

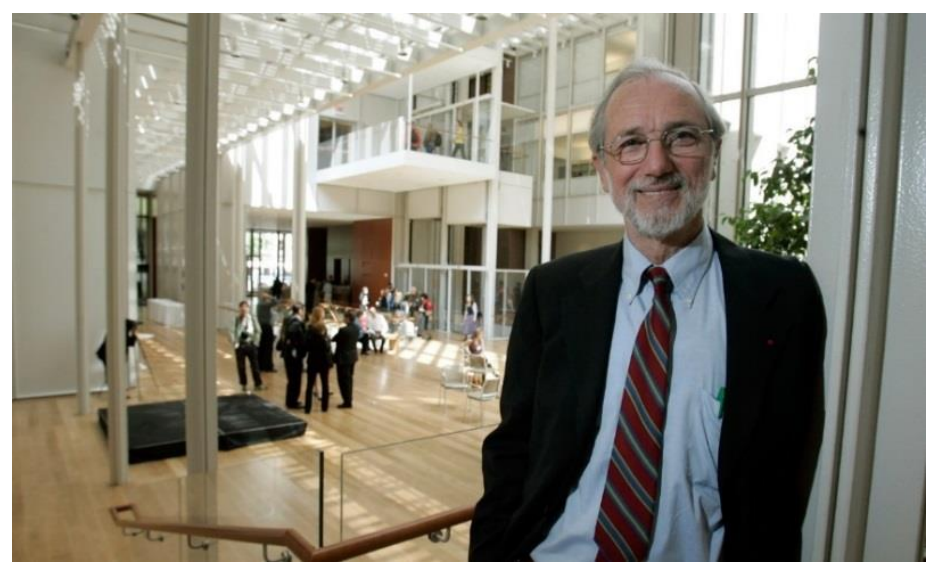


Segundo Anaconi (2018), em 1971 o escritório Piano \& Rogers começa a atuar em Londres com Richard Rogers; juntos, eles ganharam o concurso para o Centro Pompidou e posteriormente muda-se para Paris, a partir disto, desta parceria surge uma série de projetos de edifícios na Itália e Inglaterra.

A partir de 1977, firma parceria com o arquiteto Peter Rice em sociedade no escritório "Piano \& Rice", a qual perdurou até 1993, com a morte de Rice. No entanto, juntamente aos trabalhos com Rice, Renzo Piano funda em 1981 seu escritório próprio, o Renzo Piano Building Workshop. Algumas obras de Renzo Piano possuem aspectos futurísticos. É comum a utilização de materiais como o vidro, iluminação, metal e traços retos - inclusive apontados como obras de arquitetura High Tech. Entretanto, outros trabalhos podem ser considerados conservadores e é esta condição de não se enquadrar em nenhuma categoria que faz dele um exemplo de pluralidade e motivo a ser vencedor de diversos prêmios. (BENÉVOLO, 2007).

Para Benévolo (2007), como a maioria das obras projetadas por membros da corrente de arquitetura "High Tech", Piano estabelece a tecnologia como ponto de partida para seus projetos. Mas ultimamente tem sido diferente, ele modificou suas tentativas de gerar um caráter arquitetônico baseado somente em formas tecnológicas, mas também apresenta preocupação com o conforto e as necessidades do usuário. Em seus trabalhos mais recentes, Piano aplicou seus experimentos estruturais para uma série de projetos sociais e cívicos.

O talento singular de Renzo Piano tem origem estritamente tecnológica e quase artesanal, totalmente anômala no ambiente italiano, onde quase todos os arquitetos modernos, desde os anos de 1930, têm uma formação humanística, ligada à polêmica modernista e às sucessivas revisões. (BENÉVOLO, 2007).
Sua primeira obra famosa é o Centro Cultural Georges Pompidou, que fica em Paris. Entretanto, podemos citar ainda outros projetos bastante conhecidos, como o Centro Cultural Jean-Marie Tjibaou, na Nova Caledônia; o edifício-sede do jornal The New York Times, em Nova York; o edifício The Shard, em Londres - o edifício mais alto da Europa -; e a Academia de Ciências da Califórnia. $O$ edifício The Shard é uma construção enorme, com 306 metros de altura, 86 andares e uma moderna fachada de vidro. Mas seus números colossais não são os únicos atrativos: com o uso de tecnologia de ponta, o edifício gasta $30 \%$ menos energia do que seus semelhantes, maximiza a entrada de luz e possui estufas de ventilação natural em cada andar. Um verdadeiro monumento High Tech. (ANACONI, 2018)

Já a Academia de Ciências da Califórnia é destaque como modelo de uma floresta indoor, telhado verde com mudas nativas que minimizam o calor no interior do edifício e absorção de $60 \%$ da água da chuva para reaproveitamento. Além disso, cerca de $20 \%$ da energia elétrica da Academia é solar, e $50 \%$ dos materiais utilizados em sua construção foram reciclados de outras construções, um exemplo do uso de tecnologias sustentáveis e de forma totalmente diferente da construção em Londres. (ANACONI, 2018).

Algumas obras:

The Shard, também conhecida como London Brigde Tower, é uma torre de uso misto com 72 pavimentos localizada junto a estação London Brigde, às margens do rio Tâmisa. Esse projeto foi uma resposta à visão urbana do prefeito de Londres Ken Livingstone e à sua política de fomentar o desenvolvimento de alta densidade nos principais modos de transporte em Londres. Esse tipo de extensão urbana sustentável está baseada na proximidade do transporte público, desencorajando o uso do automóvel e ajudando a reduzir o tráfego na cidade. (ARCHDAILY, 2012). 
Figura 2. The Shard, Renzo Piano.

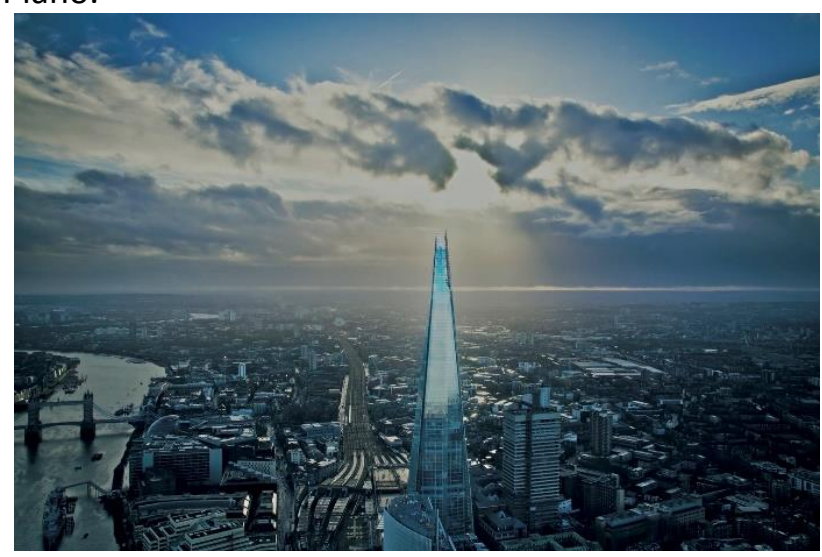

Fonte: Archidaily, 2012.

O Centro Cultural Jean-Marie Tibaou, projetado pela RPBW é um conjunto de "cabanas", pequenos pavilhões e espaços cheios de árvores. Está localizada em um cuspe de terra chamado Península Tina, cercada por água em três lados. A exuberante vegetação do local é cortada com trilhas e caminhos, entre os quais há "aldeias": aglomerados de edifícios com fortes laços com seu contexto, seu layout semicircular definindo áreas comuns abertas. (ARCH2O, 2020).

Figura 3. Centro Cultura Jean-Marie Tibaou, Renzo Piano.

Fonte: Arch2o, 2020.

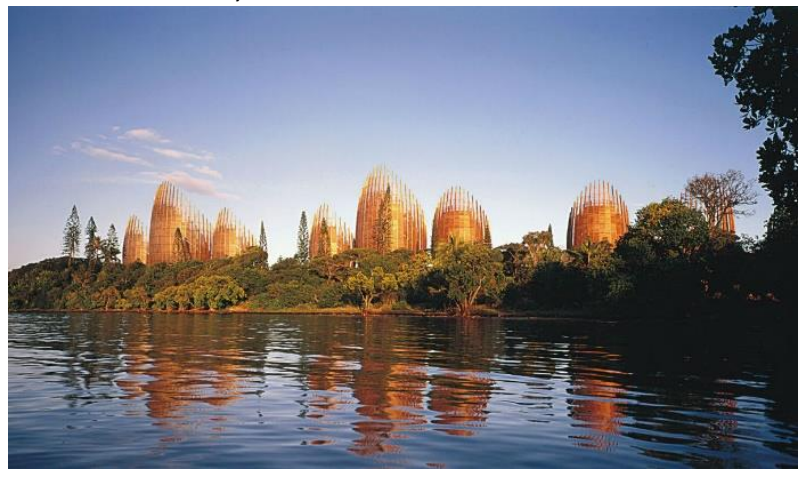

Um ícone arquitetônico imediato de Paris - o Centro Nacional d'Art et de cultura GeorgesPompidou (Centre Pompidou, ou Beaubourg) - é uma vasta estrutura multidisciplinar, uma fábrica de cultura que preserva e exibe importantes coleções de arte moderna. É um lugar onde as muitas vertentes da cultura contemporânea se entrelaçam: arte, design, literatura, música e cinema. O centro é como uma enorme nave espacial feita de vidro, aço e tubos coloridos que pousaram inesperadamente no coração de Paris, e onde rapidamente estabeleceria raízes profundas. (RPBW Archtects, 2020b). 
Figura 4. Centro Cultural Georges Pompidou

Fonte: Archdaily, 2012.

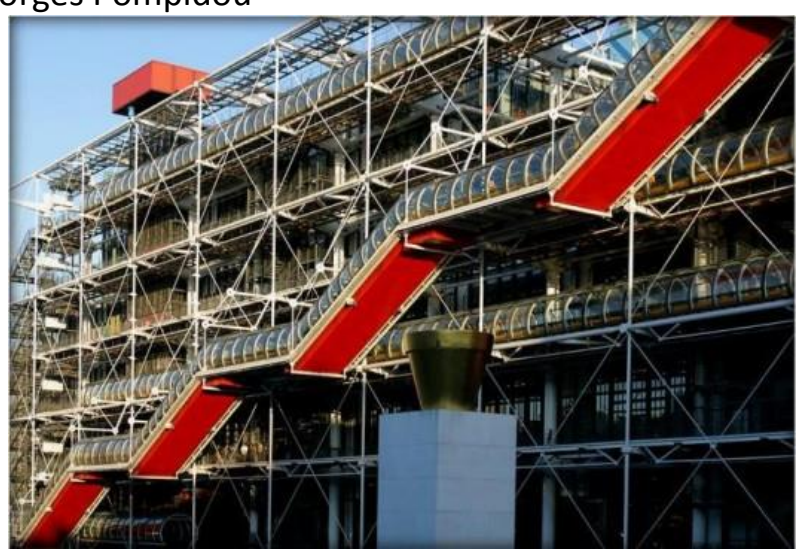

Uma nova sede do jornal "New York Times" foi encomendada via competição convidada em 2000. O projeto vencedor da Renzo Piano Building Workshop abre um canto negligenciado de Manhattan em frente à Autoridade Portuária, com um edifício de 52 andares cujos temas de permeabilidade e transparência expressam a ligação intrínseca entre o jornal e a cidade. (RPBW Archtects, 2020d).

Figura 5. The New York Times, Renzo Piano.

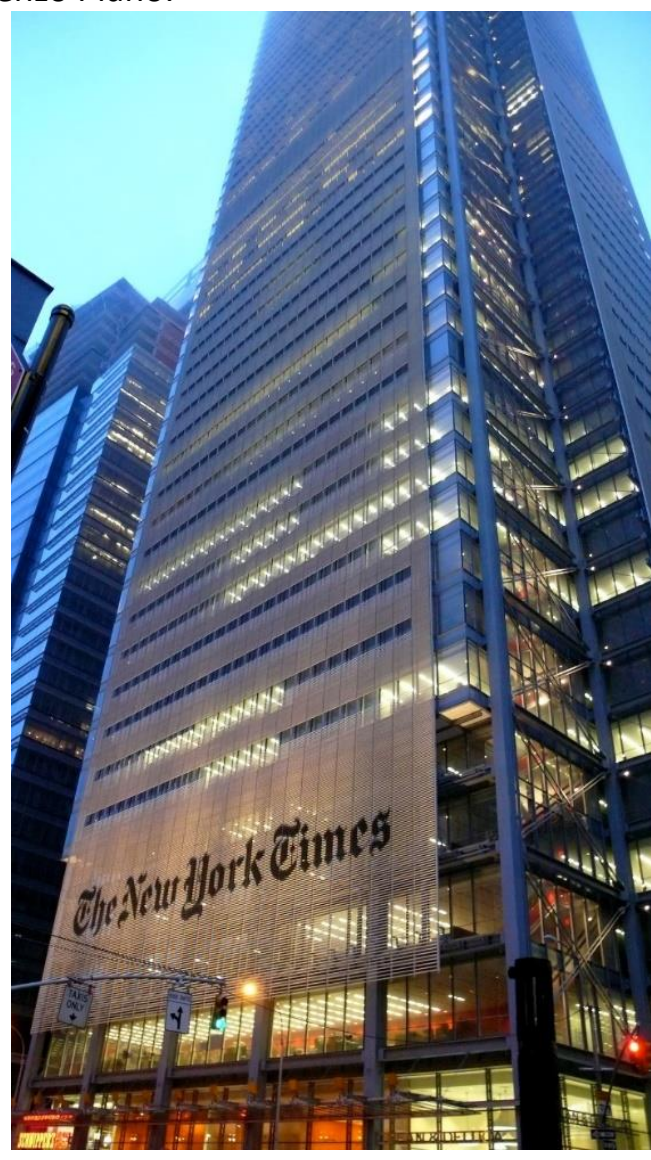

Fonte: RPBW Archtects, $2020 \mathrm{~d}$. 


\section{DISCUSSÃO}

A seguir, serão analisadas e comparadas duas obras de grade expressão de Renzo Piano, observando as semelhanças entre os projetos e a evolução cronológica do High Tech para o Eco Tech.
CENTRO NACIONAL DE CIÊNCIA E TECNOLOGIA NEMO

O Museu fica localizado no centro da cidade de Amsterdã, na Holanda, sobre o túnel rodoviário subterrâneo que une os lados norte e sul da capital, e teve sua construção realizada entre os anos de 1992 e 1997. (RPBW Archtects, 2020c, p. 2).

Figura 6 e 7. Mapa mundi identificando Holanda, Mapa da Holanda

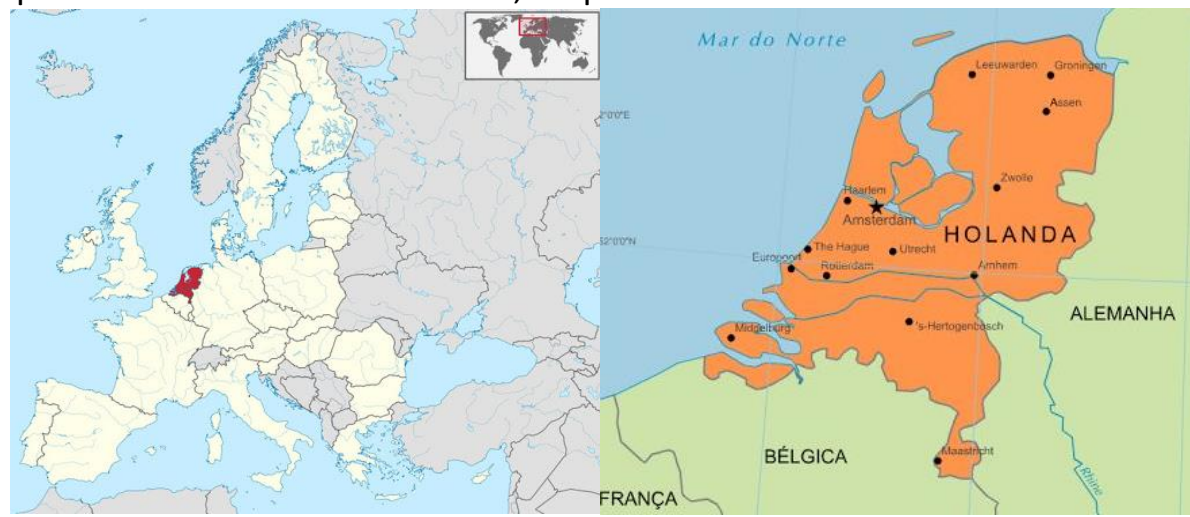

Fonte: Portal de Holambra, Morar e Viajar, 2020.

Figura 8. NEMO - Implantação. Sem escala.

túnel

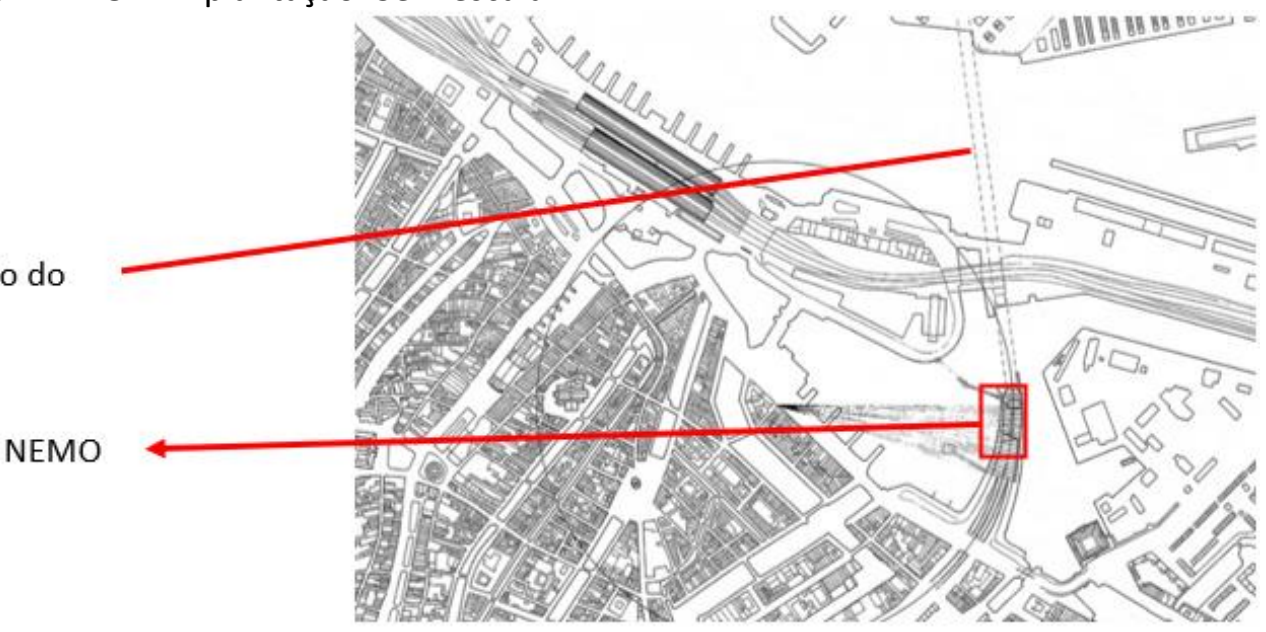

Fonte: Archiweb, modificada pelos autores, 2020.

O projeto tem como conceito relacionarse com o seu entorno através da forma, funções e usos que ele apresenta, trazendo um ponto de encontro para a cidade. A partir disso surge seu partido, que ao apresentar o formato semelhante ao de um navio, se relaciona com todo o sistema portuário que se encontra ao redor, seu formato ainda permite a criação de uma praça em sua cobertura, o que une as pessoas à obra e as proporciona um mirante. (RPBW Archtects, 2020c).

Como discorrido durante a análise do conceito e partido do museu, sua relação com o lugar se dá principalmente sobre os usos, e a partir dessa premissa surge a forma como resposta. Suas cores e revestimentos também possuem relação com o partido, reforçando a ideia da semelhança a um navio.

A construção do NEMO apresentou ao arquiteto italiano Renzo Piano um grande desafio: o museu teve que ser construído no topo de um túnel. A curvatura do túnel serviu de base e também foi a inspiração para a forma 
curva do próprio edifício.

Em uma espécie de imagem

matematicamente

refletida do tráfego que desce para o túnel, o arquiteto projetou um edifício que parece sair da água. (NEMO SCIENCE MUSEUM, 2020, p. 2).
Sendo assim, pode-se entender que o NEMO funciona como um elo que liga e reflete diretamente os principais elementos do lugar onde ele se encontra, criando uma conversação direta entre as pessoas, o túnel, a paisagem e os portos que o circundam.

Figura 9. NEMO, vista do museu.

Fonte: BIANCHINI, 2018.

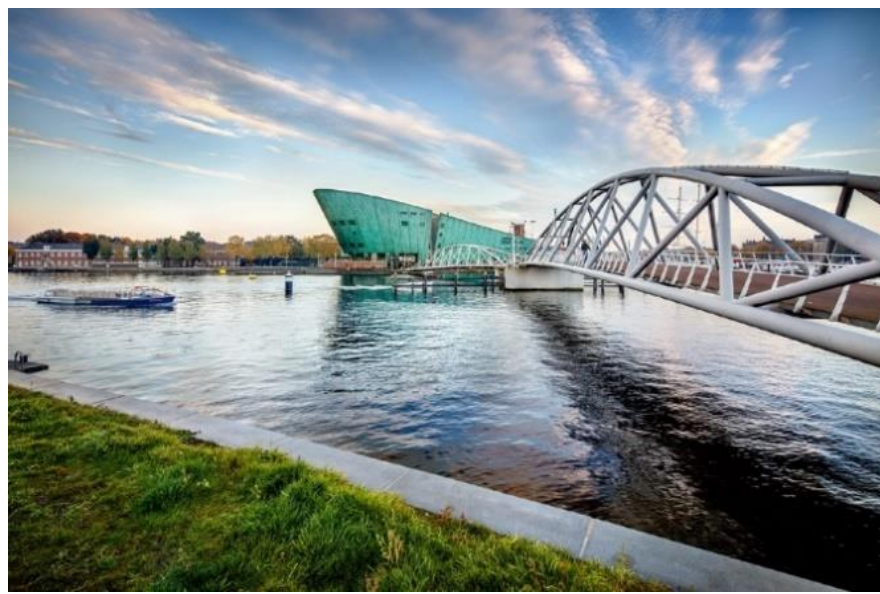

O edifício possui uma forma bastante diferente e chamativa, o que pode ser observado em outras obras do Arquiteto. É uma construção única, que revela a mente genial do projetista ao entregar um trabalho tão descomplicado, mas que possui tamanha comunicação com a cidade.

De longe, o artefato é uma aparição mágica, carregada de assonâncias díspares, construtivas e navais. De perto, oferece uma pluralidade sugestiva de caminhos internos e externos, que culminam na aconchegante cobertura trafegável, único lugar de descanso e relaxamento em meio às áreas do porto. (BENÉVOLO, 2007, p. 172).

Figura 10. NEMO, Planta do segundo andar, Sem escala.

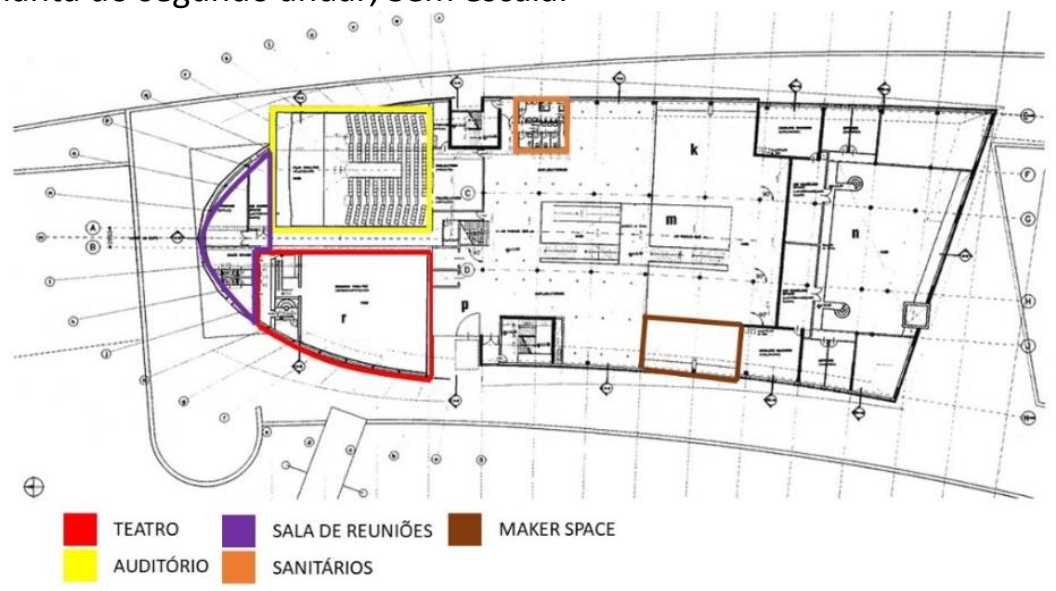

Fonte: Archiweb, modificada pelos autores, 2020. 
Figura 11. NEMO, Corte, Sem escala.

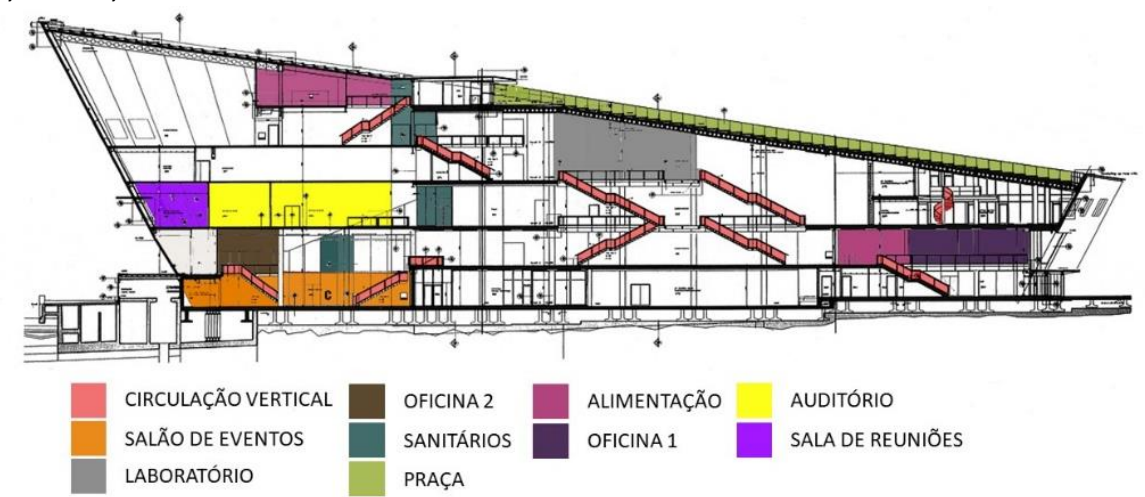

Fonte: Archiweb, modificada pelos autores, 2020.

A estrutura do museu segue a forma do túnel que passa sob ele, limitando-se em muitos aspectos ao seu formato curvo, no entanto, diversas escolhas foram pensadas com a intenção de aproximar essa estrutura aos fins que se pretendia pelo conceito da obra, como por exemplo suas cores e as disposições e formas das janelas, pequenas formas que remetem à escotilhas dos navios. "Cercado por água, o edifício tem [...] fachadas revestidas de cobre pré-oxidadas. Uma rampa para pedestres leva até o telhado inclinado do edifício, que serve como uma praça pública [...]." (RPBW Archtects, 2020c, p. 2).

Figura 12. NEMO, Corte, Sem escala.

eStRUTURA DO TÚNEL

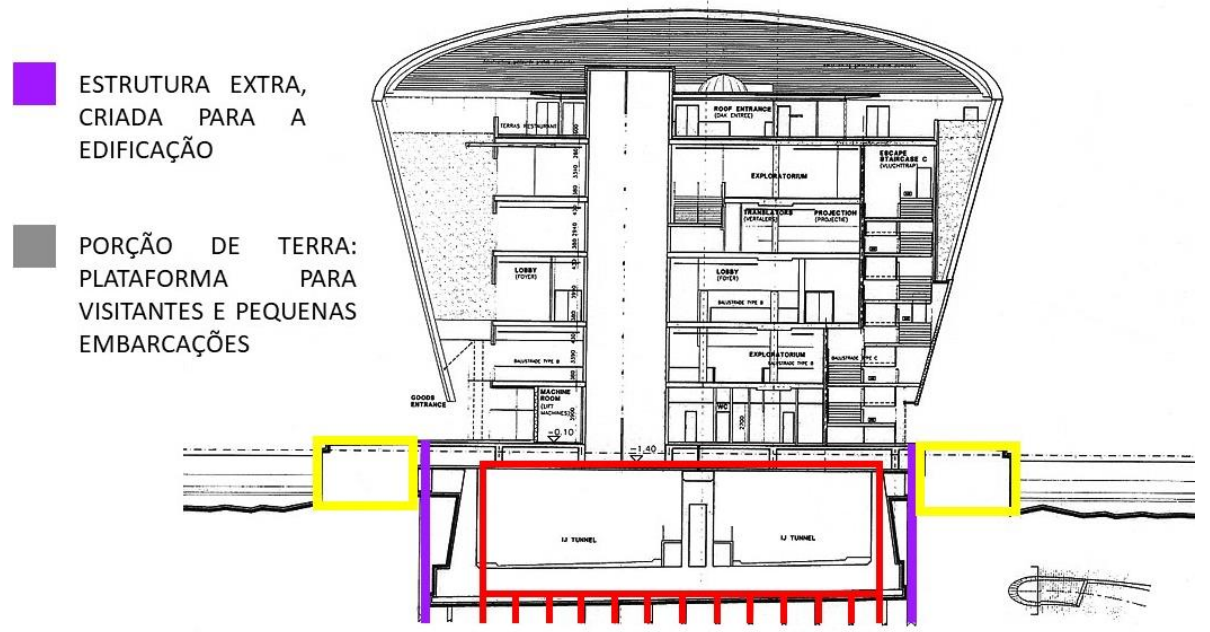

Fonte: Archiweb, modificada pelos autores, 2020.

A tectônica do museu é a relação do conjunto como um todo, funcionando de forma a contribuir para uma expressão única, criando no porto de Amsterdã um novo significado. A estrutura sobre o túnel, criando a forma curva que dialoga com a paisagem, em junção da praça, que por sua vez cria uma relação entre as pessoas e a cidade, como um mirante dedicado a ela. As inclinações, a forma, que se assemelha ao casco de um barco, todos tornando possível a existência do museu tão única como é. "O museu de Amsterdã, talvez a mais excelente no grupo dessas obras de fim de século, emerge sobre a entrada de um túnel rodoviário e desenvolve em elevação esse delicado motivo, criando no meio da água um lugar que não existia." (BENÉVOLO, 2007, p. 172).

\section{ACADEMIA DE CIÊNCIAS DA CALIFÓRNIA}

A Academia de Ciências Naturais da Califórnia, fundada em 1853, está situada no Golden Gate Park, em São Francisco, desde 1976. 
Contemplando dois edifícios, o Steinhart Aqurium e o Morrinson Planetarium, é um dos maiores museus de história natural do mundo. Foi completamente reconstruído em 2008, com um projeto do arquiteto italiano Renzo Piano, recuperando as antigas construções misturando- as com uma nova estrutura transparente que o conecta com o Golden Gate Park. (PAIVA, 2017, s/p.).

Figura 13. Mapa EUA e Califórnia, Localização.
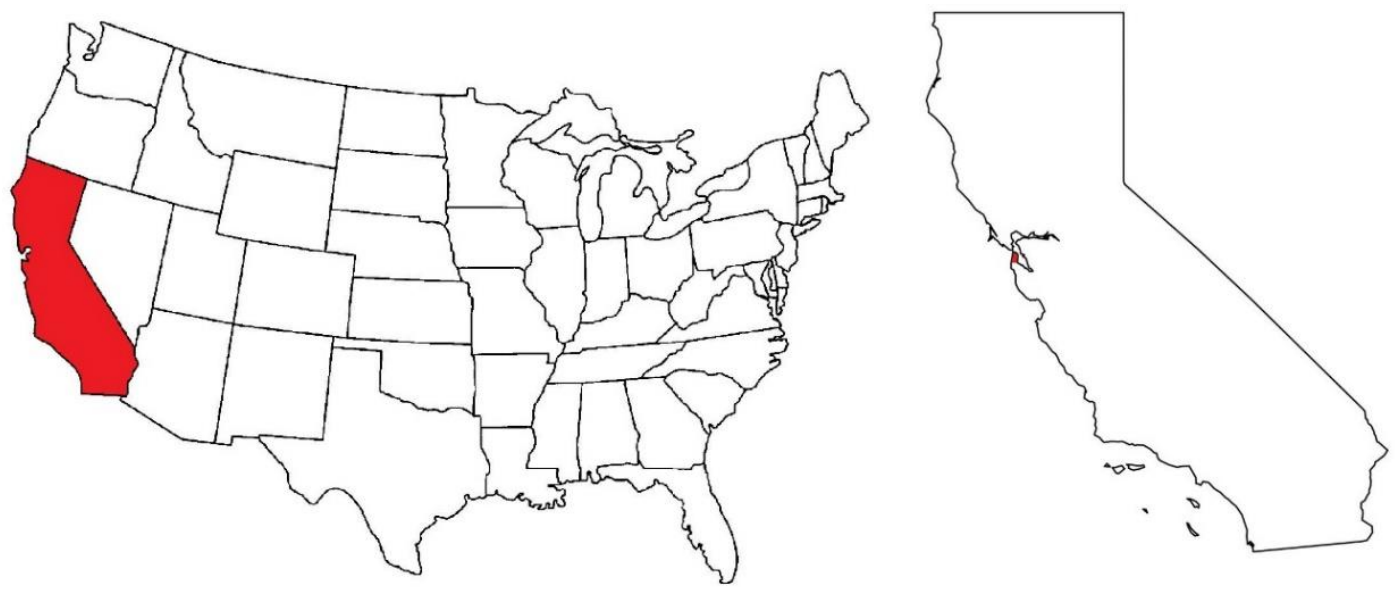

Fonte: Maps EUA, modificada pelos autores, 2020.

Figura 14. Academia de Ciências da Califórnia, vista aérea.

Fonte: ArchDaily, 2019.

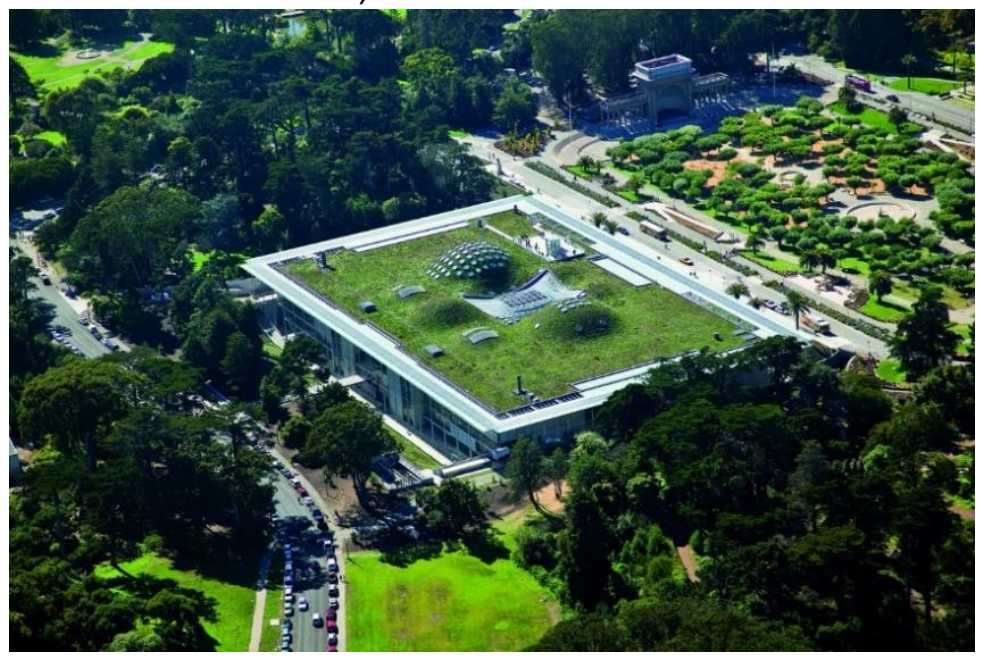

Segundo Delaqua (2012, s/p.), a sustentabilidade foi o fundamento básico do projeto, sendo assim "Green Building", consumindo entre 30 e $35 \%$ menos energia. 0 projeto abriga um planetário, um museu de história natural e um aquário, além de instalações de pesquisa e ensino. O planetário e a "bolha" que contém o habitat da floresta tropical são as duas grandes esferas que formam o telhado verde. O teto se torna uma paisagem com espécies nativas da Califórnia, que não precisará de manutenção extra ou água, atraindo espécies locais para ocupá-lo. Assim, o telhado verde não será totalmente acessível para os visitantes, que só podem percorrer um pequeno caminho na cobertura.
A natureza não foi feita à medida do homem. [...] Se o homem não se proteger da natureza, esta acabará com ele. Por isso, a relação com a natureza conforma um terreno ambíguo que leva o homem a criar uma segunda natureza para poder fazê-la sua. [...] 
Ocorre, entretanto, que a natureza original é tão forte que somente interpretando-a, somente a partir de suas próprias normas, pode-se criar outra. A sustentabilidade consiste em construir pensando no futuro, não somente tendo em conta a resistência física de um edifício, senão pensando também em sua resistência estilística, nos usos do futuro e na resistência do próprio planeta e de seus recursos naturais. (PIANO, 1998, p. 60).

Desenhado com linhas simples e contínuas, o edifício alcança uma leveza única, sendo assim inserido na paisagem local, adaptando-se e conversando com o relevo. Sua cobertura ondulada apresenta-se como parte do terreno, totalmente integrada a ele, como se dali tivesse nascido. A nova sede transmite, através da arquitetura, sua paixão pela natureza e pelo conhecimento da natureza. (RPBW Archtects, 2020a, s/p.).

Figura 15. Academia de Ciências da Califórnia, relação com a natureza

Fonte: ArchDaily, 2012.

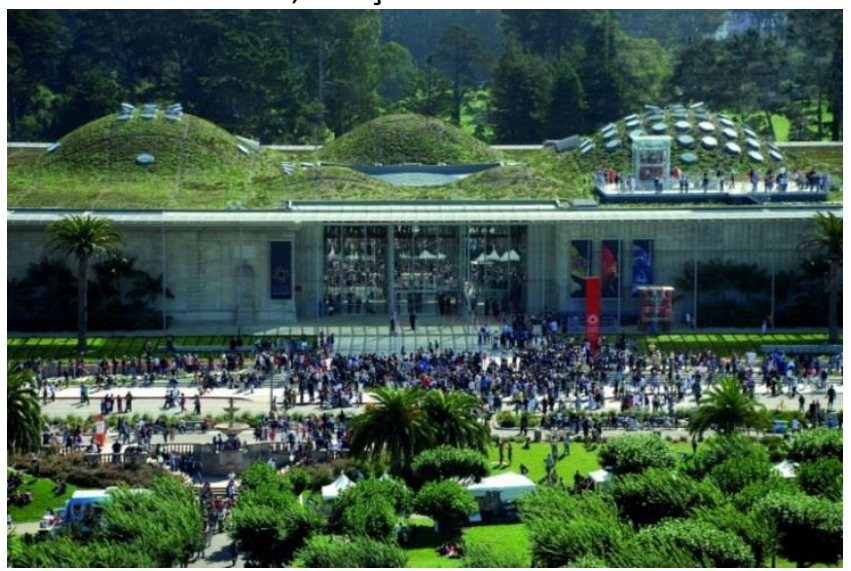

Segundo Piano (RPBW Archtects, 2020a, s/p.), "Este museu sempre trabalhou em três níveis - exibindo a coleção, educando o público, pesquisando a ciência. O espírito deste novo edifício é anunciar e reforçar essa complexidade de função". Esse projeto engloba o público visitante e as funções restritas a pesquisa e desenvolvimento científico. Assim, evidencia a simplicidade da planta retangular, com os espaços bem integrados, todos eles voltados para uma praça central.

Figura 16. Academia de Ciências da Califórnia, Corte e Setorizacão.

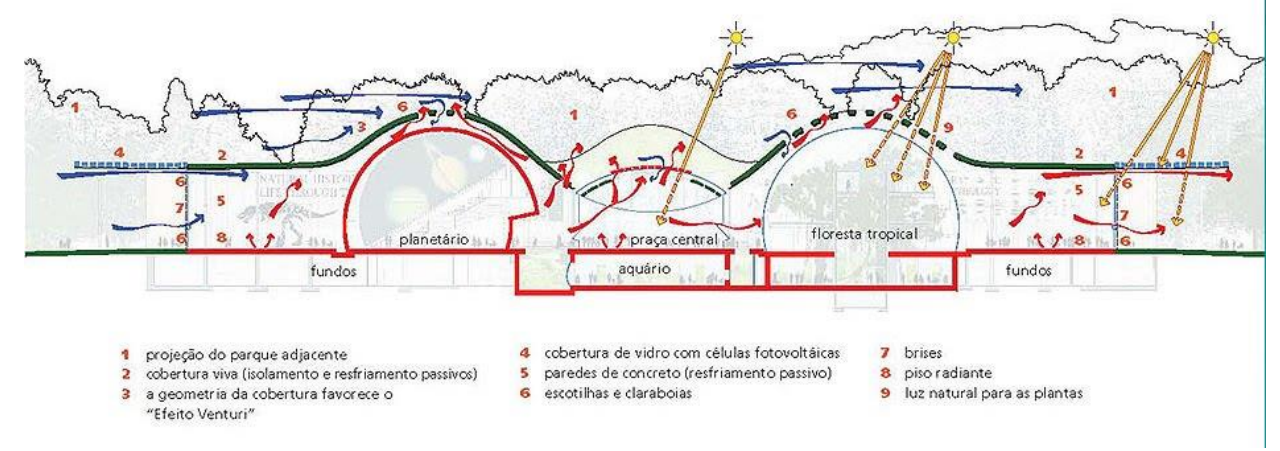

Fonte: +ArchCultura, 2010. 
Figura 17. Academia de Ciências da Califórnia, Planta e Setorizacão.
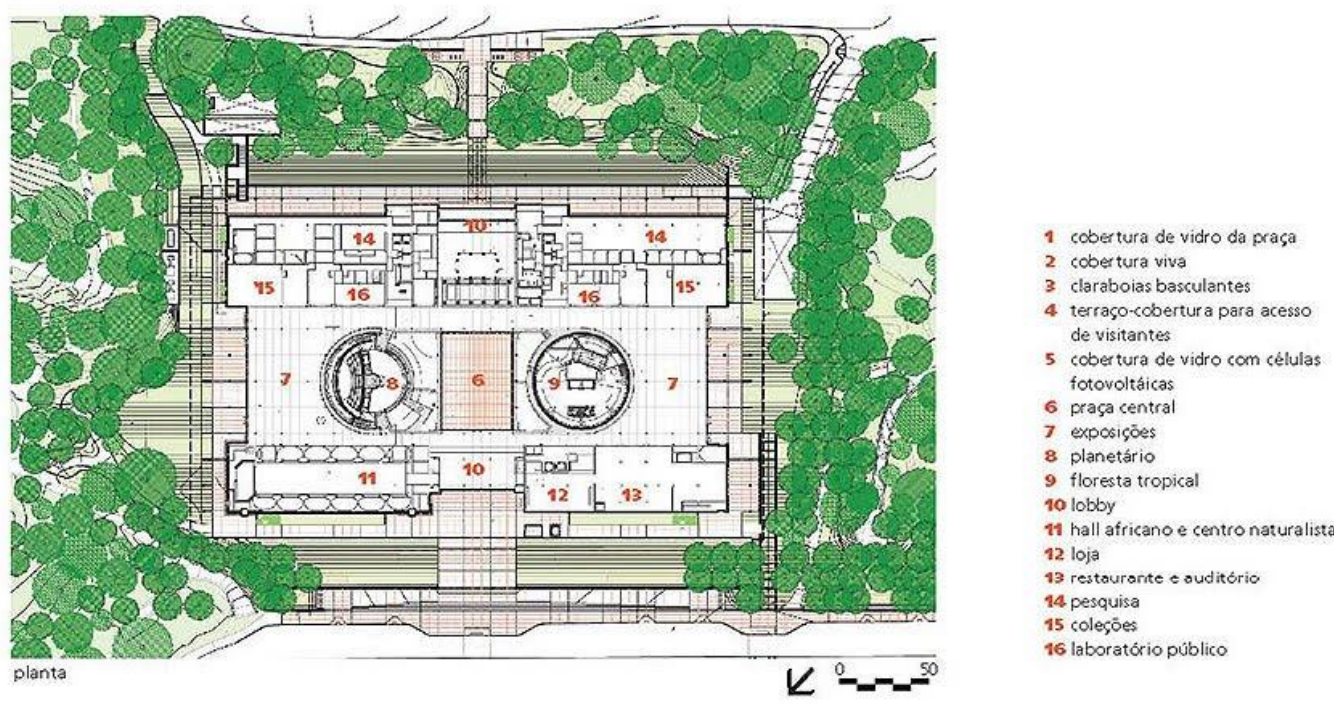

Fonte: +ArchCultura, 2010.

Renzo trabalha formas circulares inseridas em um retângulo, primeiramente desenhando uma linha contínua, na qual depois faz curvas subindo e descendo, formando o detalhe da cobertura ondulada, com uma cúpula com claraboias. Soma-se a isso o beiral de estrutura metálica com células fotovoltaicas. Assim, fica nítido o partido arquitetônico do projeto, do edifício conectado ao local. Com grandes vãos envidraçados, que permitem os visitantes a contemplar a paisagem verde ao redor, a sensação de pertencimento fica ainda mais evidente. (RPBW Archtects, 2020a, s/p.).

Museus em geral não são transparentes. Mas nesse caso ele se situa no meio de um belo parque, então os visitantes vão querer olhar para fora e ver onde estão [...] Criamos um museu visual e funcionalmente ligado ao entorno natural, levantando

metaforicamente um pedaço do parque e colocando uma construção sob ele. Com a arquitetura sustentável e desenho inovador, adicionamos um elemento vital ao parque. (PIANO, RPBW Archtects, 2020a, s/p.).

Para Paiva (2017, s/p.), a cobertura também conta com espécies vegetais nativas, resistentes à seca e que não precisam de irrigação. No centro do telhado verde, sobre a praça, foi colocado uma grande claraboia de vidro, e outras menores, espalhadas pelo telhado, permitindo iluminação natural nos espaços. Mas o grande charme do projeto está na articulação entre os componentes de aço e vidro. 
Figura 18. Academia de Ciências da Califórnia, detalhe telhado verde.

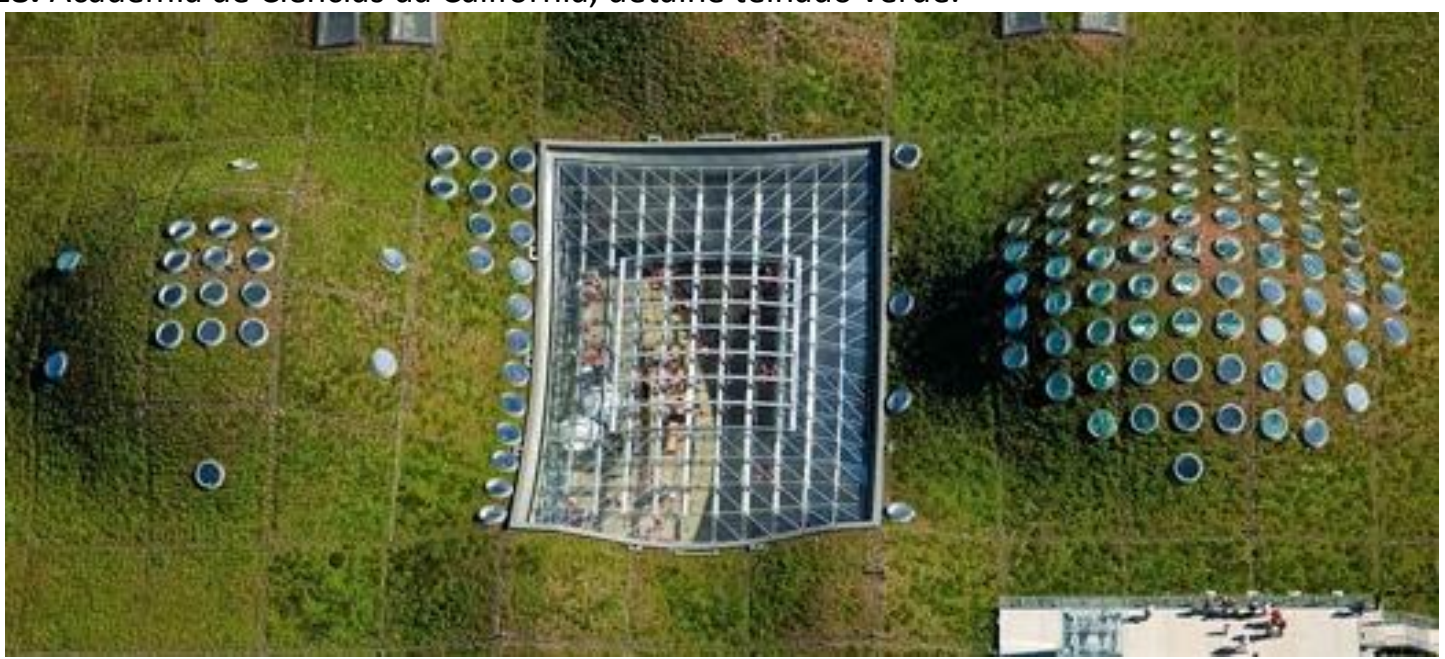

Fonte: RPBW Archtects, 2020a.

\section{ANÁLISE COMPARATIVA DAS OBRAS EM ESTUDO SOB OS ASPECTOS DO HIGH TECH PARA O ECO TECH}

Quando pensando em ambas as obras pelo mesmo ponto de vista High Tech, pode-se dizer que elas se assemelham na questão de suas formas e estruturas surgirem em decorrência total do terreno em que estão inseridas. Há uma relação forte por parte das duas obras com o local, suscitando a sensação de que elas pertencem a ele indiscutivelmente. Além disso, os usos e intenções são bastante parecidos uma vez que são edifícios pensados para as pessoas, em larga escala, e a educação e ampliação do catálogo cultural que são capazes e previstos para fornecer aos seus visitantes.

Alguns aspectos semelhantes podem ser observados em suas formas, mesmo em pequenos detalhes como a presença de linhas curvas e as pequenas janelas, que mesmo na segunda obra remetem a escotilhas, elemento encontrado nos navios que a primeira tanto se parece. São de implantação bruta, com seus detalhes estruturais e materiais expostos propositalmente ajudando a compor a apresentação nua dos edifícios.

No que diz respeito ao Eco Tech, é nítido o cuidado do arquiteto com a sustentabilidade e o conforto térmico, sendo presente no NEMO vegetação em parte de sua cobertura, ajudando na manutenção da temperatura do Museu e tornando o ambiente da praça mais agradável às pessoas. A preocupação e cuidado com esses aspectos aumentam e se tornam mais presentes na segunda obra, apresentando uma ótima eficiência energética e conforto térmico.
Esteticamente também se observa a fusão com o parque, conferindo uma aparência bastante natural.

Diante das ponderações deste artigo, observa-se que Renzo Piano, contribui significadamente através de uma arquitetura à serviço da sociedade, com uma pluralidade de estilos, mediante projetos que surgem da especificidade de cada lugar. $O$ arquiteto explora ao máximo cada situação e suas condicionantes, baseadas em idéias contextualizadas com preocupações reais, fazendo o uso da luz, ventilação natural e sustentabilidade, dando características únicas, com produções heterogêneas e diversificadas, expressadas através do uso da alta tecnologia e moldados ao contexto de cada projeto, mediante um processo reflexivo em busca do equilíbrio e suas particularidades.

Podemos apontar a Academia de Ciências na Califórnia - cujo lugar possui um senso coletivo com o meio ambiente - projetado com uma linguagem voltada para $o$ presente, que transmite paixão pelo conhecimento e pela natureza. No Museu Nemo, cercado por água como se estivesse ancorado no Porto de Amsterdã, o edifício possui uma forma de navio e fachadas revestidas de cobre pré-oxidadas. Para Piano, a arquitetura não deve ser imposta, mas se relacionar com o lugar de forma "natural" e qualitativa, com o aproveitamento para o qual o projeto foi designado, considerando aquilo que o precede, beneficiando a sociedade atual e vindoura. 


\section{AGRADECIMENTOS}

À Universidade, por nos possibilitar a oportunidade de participar de eventos que ampliam nosso conhecimento.

À professora Korina Costa, nossa orientadora, pelos direcionamentos para a elaboração do presente artigo e por nos incentivar a apresentá-lo no ENEPE.

A nossos amigos e familiares, pelo apoio incondicional, sem os quais a realização deste trabalho não seria possível.

\section{REFERÊNCIAS}

ANACONI, Gregório Luiz. A Surpreendente Arquitetura de Renzo Piano. 2018. Portal 44 Arquitetura. Disponível em: http://44arquitetura.com.br/2018/03/renzopiano-biografia-e-obra/. Acesso em: 20 mar. 2020.

ARCH2O. Jean-Marie Tibaou Cultural Center/Renzo Piano Building Workshop. Arch2o. 2020. Disponível em: https://www.arch2o.com/jean-marie-tjibaoucultural-center-renzo-piano-building-workshop/. Acesso em 18 ago. 2020.

ARCHCULTURA. São Francisco abre as portas do museu mais verde do mundo: California Academy of Sciences. ArchCultura. Acessado em 18 de Ago de 2020. <http://archcultura.blogspot.com/2010/05/saofrancisco-abre-as-portas-do-museu.html>

ARCHDAILY. The Shard/Renzo Piano Building Workshop. ArchDaily Brasil. 2012. Disponível em: https://www.archdaily.com.br/br/890529/theshard-renzo-piano-building-workshop. Acesso em 18 ago 2020.

ARCHIWEBZ. NEMO. ArchiWebz. Acessado em 18 de Ago de 2020 <https://www.archiweb.cz/en/b/nemo-narodnicentrum-pro-vedu-a-techniku>

BENÉVOLO, Leonardo. A Arquitetura no Novo Milênio. São Paulo: Estação Liberdade, 2007.

BIANCHINI, Riccardo. Nemo Amsterdam - Museo della Scienza. Inexhibit. Acessado em 18 de Ago de 2020. $<$ https://www.inexhibit.com/it/mymuseum/nem o-museo-della-scienza-amsterdam/>
DELAQUA, Victor. Academia de Ciências da Califórnia/Renzo Piano. ArchDaily Brasil. 2012. Disponível em: https://www.archdaily.com.br/br/0150160/academia-de-ciencias-da-california-renzopiano. Acesso em: 20 mar. 2020.

COLIN, Sílvio. Uma introdução à Arquitetura. Rio de Janeiro: Uape, 2000.

FRAMPTON, Kenneth. História Crítica da Arquitetura Moderna. São Paulo: Martins Fontes, 1997.

MAPS USA. Mapa do contorno dos Estados Unidos. Maps USA. Acessado em 18 de Ago de 2020. <https://pt.maps-usa.com/mapa-decontorno-dos-eua>

MORAR \& VIAJAR. Descubra detalhes sobre o mapa da Holanda. Morar \& Viajar. Acessado em 18 de Ago de $2020<$ https://morareviajar.net/omapa-da-holanda/>

NEMO. NEMO Science Museum. 2020. Disponível em: https://www.nemosciencemuseum.nl/en/aboutnemo/organization/nemosciencemuseum/buildin g/. Acesso em: 19 mar. 2020.

PAIVA, Cida. Renzo Piano e Stantec Architecture: Academia de Ciências, Califórnia. Revista Finestra, n. 68, 2017.

PORTAL DE HOLAMBRA. O mais completo e atualizado site de Holambra. Portal de Holambra. Acessado em 18 de Ago de 2020 < http://www.portaldeholambra.com.br/perfil1.ht $\mathrm{ml}>$

RPBW Archtects. Academia de Ciências da Califórnia. 2020a. Disponível em: http://www.rpbw.com/project/californiaacademy-of-sciences. Acesso em: 21 mar. 2020.

RPBW Archtects. Centro Georges Pompidou. 2020b. Disponível em: http://www.rpbw.com/project/centre-georgespompidou. Acesso em: 18 ago. 2020.

RPBW Archtects. NEMO. Centro Nacional de Ciência e Tecnologia. 2020c. Disponível em: https://www.nemosciencemuseum.nl/en/about- 
nemo/organization/nemosciencemuseum/buildin g/. Acesso em: 19 mar. 2020.

RPBW Archtects. The New York Times Building. 2020d.

Disponível em:

http://www.rpbw.com/project/the-new-york-

times-building. Acesso em: 18 ago. 2020. 